\title{
OBSERVAÇÕES SOBRE A SITUAÇÃO DO \\ TRABALHADOR RURAL PRESO NO POLÍGONO DA MACONHA DO BRASIL
}

\section{Erika Macedo Moreira}

e-mail: erika_adv@ig.com.br.

RESUMO: A partir de uma leitura da política de combate às drogas segundo os marcos do capitalismo, analisam-se as condições objetivas e subjetivas que favoreceram a consolidação do cultivo da maconha na região do Submédio São Francisco em escala comercial e que fizeram com que os trabalhadores rurais da região constituíssem um exército de excluídos facilmente cooptados pelo "narconegócio". Assim, este trabalho problematiza a prisão do trabalhador rural no cultivo da cannabis sativa como traficante. Na região onde se desenvolve o cultivo, registra-se a trajetória dos trabalhadores rurais, atingidos pela barragem de Itaparica e organizados em torno do Pólo Sindical, na luta pela garantia de acesso aos meios de produção. O Estado brasileiro, ao identificar que a região é um pólo produtor de substância qualificada como ilícita, institucionaliza a região como o Polígono da Maconha do Brasil e orquestra uma ação que conjuga políticas para a região: a repressão mediante operações de erradicação e o desenvolvimento social por meio da Reforma Agrária. A partir do resgate do direito de punir do Estado, das précondições que favoreceram a expansão do cultivo, da análise dos efeitos da política e, sobretudo, do conjunto de razões que levam o trabalhador rural a estar relacionado ao cultivo, busca-se atribuir um tratamento legal diferenciado ao trabalhador rural, considerando as causas que podem excluir a punibilidade.

PALAVRAS-CHAVE: Criminalização; Proibicionismo; Geopolítica das drogas; Direito ao trabalho. 


\section{INTRODUÇÃO}

A construção da presente reflexão ${ }^{1}$ deu-se a partir de trabalho de campo vinculado a um estudo sociológico na região identificada pela mídia como o "Polígono da Maconha" - na qualidade de assistente de pesquisa, assumindo a dimensão jurídica do levantamento de dados, quando pude realizar entrevistas ${ }^{2}$ com autoridades públicas em diferentes funções: diretamente relacionadas às políticas de repressão ao tráfico, ligadas à superintendência do INCRA, responsável pela demarcação das terras de cultivo visando expropriação para fins de reforma agrária, ligadas à Igreja e também com representantes do movimento sindical de trabalhadores rurais.

Durante a permanência na área, pude acompanhar e assessorar o Seminário de Levantamento de Direitos das Trabalhadoras e dos Trabalhadores Rurais do Submédio do São Francisco, organizado pelo Pólo Sindical. Esta participação permitiu iniciar uma indagação sobre se, embora considerado ilícito perante a lei, o cultivo da cannabis sativa imporia uma consideração sociológica necessária para a prática da lei em bases socialmente justas, juridicamente coerentes e pedagogicamente eficientes, considerando-se o aspecto restitutivo das leis em relação à sociedade e a definição de normas de conduta.

Este trabalho pretende problematizar essa consideração inicial apontando uma sugestão jurídica: a extinção da punibilidade pela excludente de ilicitude ou culpabilidade - como modelo de orientação para uma prática da lei que reforce a sociabilidade local e não gere efeitos contraditórios e conseqüências desagregadoras ou repetidoras de mecanismos de exclusão social no Brasil.

$\mathrm{Na}$ região onde se desenvolve o cultivo de cannabis em escala comercial, registra-se a trajetória de um movimento social que teve enorme visibilidade nos anos 1970, quando os trabalhadores rurais, atingidos pela barragem de Itaparica, resolveram se organizar para conseguir seu reassentamento depois de dez longos anos de negociação com o Estado. Começaram aos poucos, ocupando sindicatos

1 Baseia-se em A Despenalização doTrabalhadorRural preso no cultivo da Cannabis Sativa,apresentado como projeto de conclusão do curso de direito da Faculdade de Direito da Universidade Federal Fluminense, defendido em 09 de Agosto de 2004. 
desmobilizados, criando oposições sindicais, articulando diferentes entidades, numa região que envolvia dois estados e uma dezena de municípios. Em 1978 criaram o Pólo Sindical que agrega 15 Sindicatos de Trabalhadores Rurais da Bahia e de Pernambuco $^{3}$, e se transformaram em protagonistas da implementação dos projetos de reassentamento.

O Pólo Sindical se moveu no sentido de criar uma articulação mais orgânica dos trabalhadores atingidos por uma determinada ação específica do Estado em seu prejuízo, ou pelo menos que secundarizava seus interesses e necessidades. Muitas ações foram encaminhadas com êxito, especialmente a criação das agrovilas e dos projetos de irrigação que permitiram uma estrutura fundiária melhor distribuída e assentada na produção familiar, atuando num sentido includente em relação aos trabalhadores rurais e permitindo sua fixação na terra e nas proximidades do lago da barragem (que chamam de "terra molhada").

Importante também tematizar a vida e as escolhas dos jovens, filhos dos reassentados, que praticam uma agricultura considerada ilícita em função da planta que cultivam, mas que para eles se apresenta como trabalho. Este se realiza de modo pouco diferenciado em relação à larga maioria das formas de incorporação produtiva no campo: sem regulamentação, carteira assinada, ou qualquer direito, e ainda em condições extremamente precárias, dada a ilegalidade na qual o Estado insere este tipo de trabalho.

O objetivo central, portanto, é tentar produzir elementos para uma discussão que dê tratamento legal diferenciado ao trabalhador rural que vem sendo condenado à prisão por tráfico, levando em conta os argumentos das autoridades entrevistadas e as determinações da realidade tal qual apresentada pelos trabalhadores rurais, solidários aos que são apenados e sofredores diretos dos efeitos da política de criminalização e erradicação.

2 A partir do trabalho de campo para o projeto de Doutorado da Professora Ana Maria Motta Ribeiro sobre o cultivo da maconha no vazio do Estado no Brasil

$3 \mathrm{Na}$ Bahia os municípios de atuação do Pólo são: Paulo Afonso, Glória, Rodelas, Chorrocho, Macururé e Curaça. Em Pernambuco, Petrolândia, Ibimirim, Carnaubeira, Floresta, Belém do São Francisco, Orocó, Santa Maria da Boa Vista, Itacuruba. 


\section{O PROIBICIONISMO E O ESTADO PENAL}

O direito de punir do Estado surge com a definição política de que, a prática ou a omissão, de determinado ato constitui crime. Esta determinação tem o claro propósito de salvaguardar determinados interesses, que não necessariamente correspondam aos interesses da maioria do povo. Trata-se de uma decisão política exercida pelo Poder do Estado.

A definição do que é e o que não é crime, está diretamente ligada ao contexto histórico em
que ora determinadas condutas são criminalizadas. A construção de atos reprováveis e
maléficos à sociabilidade é um produto ideológico, para a manutenção e a reprodução de
interesses específicos. ${ }^{4}$

É o que acontece com a qualificação de substâncias como ilícitas. A origem de sua proibição está na necessidade de controlar o consumo de ópio no Sudeste Asiático. Nos fins do século XIX é realizada a Conferência de Xangai, que buscava restringir à comercialização do ópio, sem afetar os seus subprodutos. Como a Inglaterra, controlava a produção na Índia e o comércio da planta na China, ela seria a única economicamente prejudicada com as restrinções, e por isso não aderia à Conferência, tornando-a letra morta, praticamente ineficaz. Anos depois a Convenção de Haia restringe o comércio do ópio e de seus derivados industrializados, adquirindo o apoio da Inglaterra.

A cannabis sativa, conhecida como maconha, foi incluída no rol das drogas proibidas em 1936, por associação de interesses morais (maconha era considerada afrodisíaco que tinha o poder de abrir a mente), racistas (o "pito, o fumo" era visto como negócio de negro, a droga recreativa das classes marginalizadas, os brancos consumiam tabaco) e econômicos (a produção ameaçava os interesses da industria da celulose, das indústrias farmacêuticas de sintéticos e da indústria petroquímica).

$\mathrm{Na}$ perspectiva de Alessandro Baratta a violência é um produto criado, não pelos criminosos, mas pelos poderosos a fim de garantirem seus interesses:

Tendo imposto condições de desigualdade e de aproveitamento, tendo despojado violentamente populações inteiras de seus bens (como aconteceu com a expulsão dos camponeses na Europa) e da propriedade sobre seus corpos (como aconteceu com a 
escravidão dos negros na América), os grupos dominantes, então impuseram, com as leis e com o poder institucional, a manutenção daquelas condições e definiram como criminosos despossuídos errantes, os escravos desobedientes ou ociosos, os subalternos indisciplinados ou rebeldes. ${ }^{5}$

A penalização de determinadas condutas é uma decisão política, uma forma de controle social que visa a manutenção e a estabilidade dos valores e interesses dominantes na sociedade. Podemos perceber uma evolução no sistema punitivo, passando da 'Santa Inquisição' até chegar aos dias de hoje, no Estado Democrático de Direito. Nele prevalece, ou deveria prevalecer, o princípio da intervenção mínima, uma vez que a proteção da dignidade e dos direitos dos indivíduos é sua função maior (CRFB/88, art.5ํ), a fim de que possa dimensionar a esfera de sua atuação na proteção dos bens jurídicos coletivos, e, portanto, do próprio Estado. "A identificação de bens jurídicos de caráter coletivo ou institucional só pode ser admitida enquanto condição de proteção, ainda que indireta, de bens jurídicos individuais"”.

No Estado Democrático de Direito - ao contrário do Estado Liberal, que primava pela lei, e do Estado Social, que enaltecia os direitos sociais - os bens jurídicos maiores, são os direitos fundamentais. $\mathrm{O}$ direito de punir do estado surge como medida utilizada para preservar os bens jurídicos coletivos, ou seja, àqueles afetos a toda sociedade. Se não houver prejuízo ou dano à sociedade, não há que se falar em intervenção pelo Estado, sobretudo na forma persecutória e punitiva. Da mesma forma, a atuação do Estado não pode ser negativa, ou seja, em vez de provocar melhorias, causar mais danos à coletividade.

No ordenamento jurídico atual, a atividade punitiva está limitada pelos princípios da legalidade, que aspira a segurança jurídica do cidadão, pois garante a previsibilidade da intervenção do poder punitivo do Estado; da intervenção mínima, ou seja, o Estado só deverá utilizar o direito penal quando qualquer outro remédio

4 Cf. KARAM, Maria Lúcia. Redução de Danos, Ética e Lei: os danos da política proibicionista e as alternativas compromissadas com a dignidade do indivíduo. In: SAMPAIO, Christiane Moema Alves; CAMPOS, Marcelo Araújo (Org.). Drogas, dignidade \& inclusão social. A lei e a prática de redução de danos. Rio de Janeiro: Aborda, 2003.

5 BARATTA, Fernando. Prefácio. In: MALAGUTI, Vera B. Difíceis ganhos fáceis. Drogas e juventude pobre no Rio de Janeiro. Rio de Janeiro: Instituto Carioca de Criminologia: Editora Revan, 2003. p.32.

6 KARAM, op. cit., p.51. 
jurídico se revele ineficiente ${ }^{7}$; da lesividade, quer dizer, o sistema penal só pode castigar àquele que lesione direitos da sociedade.

A definição das substâncias ilícitas é decisão de competência "técnica" do Ministério da Saúde. A criminalização de determinadas substâncias, como a maconha e a cocaína, funda-se na defesa da saúde pública. Este é o bem jurídico protegido através da política proibicionista. Tal teoria parte do pressuposto de que o usuário é um "disseminador do mau" pela sua capacidade de difundir o uso nos meios/grupos em que se relaciona.

Nesse panorama, a saúde pública é utilizada como instrumento de manobra do Estado, já que a sua real afetação passaria pela geração de dano a uma coletividade. A política proibicionista, em especial a de combate ao narcotráfico, é utilizada como instrumento necessário à ampliação do poder de punir do Estado. Sob a égide da saúde pública e a espada da segurança nacional, "o Estado manipula as informações levadas à sociedade, cria um alarde social e criminaliza os excluídos (...) para que sob o pretexto da repressão ao crime, possam ser contidos os movimentos transformadores e libertadores"8.

Os meios de comunicação, sobretudo a televisão promovem a manipulação do processo comunicativo na formação da opinião pública. As campanhas produzidas pela grande mídia alimentam o pânico social. Esta leitura, estigmatizante, apresenta o usuário e/ou dependente alimentando o "narcotráfico", grande inimigo da humanidade, que institui o caos e a violência ${ }^{9}$. A mídia se utiliza de sensações e sentimentos, "concretizando" subjetividades; permitindo ao Estado formar uma oficiosa legitimidade na ampliação de seu poder punitivo.

Para Loïc Wacquant ${ }^{10}$ esta ampliação do poder punitivo do Estado, está diretamente relacionada com o projeto neoliberal e a política de hegemonia do estado penal norte-americano, expandido pelo governo Reagan (e hoje reafirmado pelo governo Bush). O Estado mínimo social/ Estado máximo penal amplia o rol de

2002. BATISTA, Nilo. Introdução crítica ao direito penal brasileiro. 8. ed. Rio de Janeiro: Editora Revan,

8 KARAM, op. cit., p.:61.

9 Não pretendo com isso negar os efeitos desastrosos dessa economia ilícita, mas tão só questionar quem será o real responsável pelo caos social.

10 WACQUANT, Loïc. A tentação penal na Europa, in Discursos sediciosos: crime, direito \& sociedade. Ano 7, no 11, $1^{\circ}$ semestre de 2000. Rio de Janeiro: Editora Revan: Instituto Carioca de Criminologia, 1998. 
categorias criminalizadas, substituindo as políticas sociais. Conforme Fernanda Vieira, "retira-se da responsabilidade do Estado, uma massa de excluídos que não tem utilidade para o capital"11.

Embora a lei pretenda proteger a saúde pública, por outro lado ela não impõe limites aos meios de comunicação, que através de campanhas das bebidas alcoólicas e dos cigarros, incitam a população à consumir drogas, consideradas lícitas. Para Acserald ${ }^{12}$ a criminalização de determinadas substâncias escamoteia os interesses farmacêuticos, "pois nem sempre o que é lícito se baseia na qualidade do produto, sendo tão prejudicial quanto o que é ilícito".

\section{O POLÍGONO DA MACONHA ${ }^{13}$}

O Submédio São Francisco é território dos trabalhadores rurais, organizados no Poló Sindical na luta pela terra. É, também, região caracterizada pela ocorrência do escândalo da mandioca divulgado pela mídia e, sobretudo, pelo que passou a ser denominado como o Polígono da Maconha - devido à concentração de áreas de cannabis sativa, e, em especial pela divulgação dadas às operações de erradicação.

Para $\mathrm{Scott}^{14}$ a região nordeste foi dividida em sub-regiões como uma estratégia de rearticulação dos poderes locais. O São Francisco adquire projeção nacional ao se reconhecer sua localização como central e estratégica para o desenvolvimento de uma agricultura irrigada e para a geração de energia.

Por volta dos anos 1970, iniciou-se a expansão da política energética (baseada na construção de barragem) e agrícola (a partir dos projetos de irrigação). O potencial hidrelétrico foi amplamente explorado a partir da construção de megaempreendimentos que impactam a sociedade e a economia local. A capacidade de

11 VIEIRA, Fernanda. Participação na mesa Direito à Resistência, abordando a transformação explícita da pena em capital, com a privatização dos sistemas penais, ocorrido em quase todos os Estados Norte Americanos e se expandindo para a Europa, In: SEMINÁRIO TRANSDISCIPLINAR EM SOCIOLOGIA E DIREITO. Niterói: PPGSD, 2003.

12 ACSERALD, Gilberta. Drogas, violência, direitos e democracia. Relatório Comitê Brasil. Belo Horizonte: Fórum Social Brasileiro-FSB: 2003.

13 O Polígono abarca principalmente os municípios de Floresta, Belém do São Francisco, Cabrobó, Orocó, Santa Maria da Boa Vista, Tacaratu, Petrolândia, Itacaruba, Caraibeiras, Lagoa Grande. Importante destacar que relatos indicam a expansão das áreas de plantio, conforme a ocorrência das operações. As operações vão chegando e as plantações migrando.

14 SCOTT, Parry R. Uma mancha nos perímetros irrigados: economia política na sub-regionalização no nordeste brasileiro. In: ZARUR, George de Cerqueira Leite (Org.). Região e nação na América Latina. Brasília: Ed UNB, 2000, p. 191. 
suporte para a produção de energia esgotou-se com a construção das barragens de Paulo Afonso I, II, III, IV, Moxotó, Sobradinho, Itaparica e, por derradeiro, a barragem do Xingó ${ }^{15}$. A estratégia de desenvolvimento social local foi paulatinamente substituída por um modelo de mercado voltado para a exportação.

As trágicas experiências de desocupação - deslocamento compulsório, indenizações irrisórias ou nulas e o descumprimento de metas de reassentamento das barragens de Sobradinho e Moxotó, propiciaram toda uma mobilização contrária à construção da barragem de Itaparica. $O$ trabalho de sindicalização das lutas por terras e direitos dos trabalhadores rurais iniciou em 1978, com intenso apoio de setores mais progressistas da Igreja Católica. A mobilização produzida pelo Pólo Sindical dos Trabalhadores Rurais do Submédio do São Francisco tem como marco o ano de 1979, quando iniciou um processo de grandes ocupações dos canteiros de obra como estratégia para a negociação dos direitos dos trabalhadores rurais. Segundo lulianelli ${ }^{16}$ foram cinco grandes ocupações, envolvendo cada uma entre dois a cinco mil trabalhadores. Em 1985 conseguiram parar por seis dias o canteiro de obras, reivindicando a conclusão das metas para a construção dos projetos de reassentamentos e tendo como lema "terra por terra na margem do lago".

Os trabalhadores rurais, através de sua atuação prática no enfrentamento da questão, foram construindo um novo espaço de legitimidade e coletivização de demandas, constituindo um sindicalismo rural distanciado da política assistencialista. E passam a intervir diretamente na elaboração das políticas públicas, tendo como bandeira a Reforma Agrária. Na perspectiva de Maria Lia Araújo, a atuação do Pólo Sindical reconfigura a estrutura de poder local. Suas ações geram legitimidade e reconhecimento na medida em que avançam e passam eles próprios a negociar seus interesses, conseguindo, assim, driblar os mecanismos de dominação da oligarquia local ${ }^{17}$.

Como decorrência às mobilizações conquistou-se o Acordo de 1986, que garantia os direitos reivindicados para o pleno reassentamento da população. Após

15 Idem, p.193.

16 IULIANELLI, Jorge Atílio Silva. O gosto bom do bode: juventude, sindicalismo, reassentamento e narcotráfico no Submédio. In: RIBEIRO, Ana Maria Motta; IULIANELLI, J. Atílio (Org.). Narcotráfico e violência no campo. Rio de Janeiro: DP\&A, 2000, p. 208 e 209.

17 ARAUJO, Maria Lia Correia de. Participação Política: Entre o Conflito e a Negociação. In: ARAÚJO, Maria Lia Correia; NETO, de Magda de Caldas; LIMA, Ana Eliza Vasconcellos (Org.). Sonhos submersos. Recife: Fundação Joaquim Nabuco: ed. Massangana, 2000, p. 89. 
dez anos do deslocamento de 40 mil pessoas, da não conclusão do projeto de construção da barragem de Itaparica ${ }^{18}$, e dos dois empréstimos de US\$ 232 milhões que teriam sido gastos nas obras, o Pólo Sindical, através da Rede Brasil de Instituições Financeiras Multilaterais, veio a denunciar "os resultados ${ }^{19}$ do Projeto Eletrobrás executado pela Chesf, financiado pelo Banco Internacional pela Reconstrução e Desenvolvimento (BIRD)" ao painel de inspeção do Banco Mundial.

A origem da maconha na região remonta a década de 1950, conforme relata Ribeiro $^{20}$, comentando pesquisa etnográfica realizada na área por Donald Pearson. Aparece em escala de subsistência, de produção esparsa para fins terapêuticos, fato inclusive reconhecido pelas autoridades públicas da região, entre elas o Superintendente da Polícia Federal de Pernambuco, que afirmou ter conhecimento do plantio da maconha na região desde a década de 1970, embora de baixa produção.

De fato, a presença do cultivo da maconha anterior ao reassentamento enquanto um valor tradicional aparece apenas de forma sutil, incipiente no decorrer das entrevistas realizadas, sendo portanto, um objeto de difícil comprovação. $O$ reconhecimento da escala agroindustrial da agricultura do ilícito inicia-se na década de 1980, quando os meios de comunicação apresentavam Pernambuco, como sendo o maior produtor de maconha no Brasil ${ }^{21}$.

O histórico de violência - acrescido à crise da cebola e do algodão, ao escândalo da mandioca, à impunidade e à própria política repressora do Estado, entre outras, propiciaram um terreno fértil para sua expansão. O escândalo da mandioca foi um grande calote dado ao Banco do Brasil. Este constituiu uma linha de crédito fácil para o financiamento da produção da mandioca, sendo que ao final descobriram que foi concedido mais financiamento do que havia de terras para se beneficiarem, e nenhum pé de mandioca havia sido plantado. A crise da cebola ocorreu no início dos anos 90, levando os produtores à falência.

18 Apenas $35 \%$ dos projetos encontravam-se inteiramente implementados. Sobre o assunto consultar VIANNA, Aurélio Jr. O painel de inspeção do banco mundial para Itaparica. In: BARROS, Flávia (Org.). Banco Mundial, participação, transparência e responsabilização. A experiência brasileira com o painel de inspeção. Brasil: Rede Brasil, 2001, p. 127.

19 Idem, p. 128 "as 'condições de produção e reprodução social' encontravam-se mais precárias do que as anteriores à construção".

20 RIBEIRO, Ana Motta. Sindicalismo, barragens e narcotráfico. In: MOREIRA, Roberto José; COSTA, Luiz Flávio de Carvalho (Org.). Mundo rural e cultura. Rio de Janeiro: Mauad, 2002.

21 In: Iulianelli, Caderno CEAS, 2000:40. 
As guerras de família, tradicionais na região, também teriam incrementado a difusão do plantio. Para o Delegado da Polícia Federal da Superintendência de Salgueiro/ $\mathrm{PE}^{22}$, o cultivo, ou melhor, a disputa pela hegemonia da produção, é mais um aspecto para possibilitar a capitalização, a fim de garantir a defesa da família. Ressalta ainda, o poder de fogo das famílias, especialmente na região de Cabrobó e Belém do São Francisco, onde a atuação das famílias se dá "de forma similar às estratégias de guerilha de Lampião"23.

A institucionalização da região como o Polígono da Maconha pelo governo, se deu pela necessidade de fornecer uma resposta eficaz à denúncia feita através de relatoria à ONU, sobre esta produção no país. Segundo o Superintende da Polícia Federal de Pernambuco ${ }^{24}$, a produção do Polígono abastece o mercado consumidor das capitais nordestinas, sendo o restante do país abastecido pela maconha do Paraguai ou de outros centros produtores do Brasil, como o Mato Grosso do Sul.

Pode-se considerar que, o despertar do Pólo Sindical da necessidade de estar discutindo a criminalização da maconha, e dos efeitos desta política para os trabalhadores rurais presos nas roças, possui dois marcos. O primeiro ocorreu com o assassinato de Fulgêncio Batista, em 1997. Liderança de uma das agrovilas que vinha denunciando, além da relação do PFL na região com o narcotráfico ${ }^{25}$; o ócio dos jovens e a previsível relação com o tráfico, na falta de perspectiva de trabalho e na busca pelos padrões de vida midiáticos. O segundo marco se deu com a descoberta de plantação de substância qualificada como ilícita em um dos projetos de irrigação, num lote abandonado.

O Polígono adquire importância para a Política de Segurança Nacional, fazendo com que o Estado orquestre uma intervenção, coordenando a política repressiva de erradicação da substância qualificada como ilícita e políticas sociais. As áreas identificadas são expropriadas e destinadas à Reforma Agrária. A inserção da temática na formulação de política pública específica permite evidenciar que o

22 Entrevista realizada em 26/08/03, na sede da Polícia Federal em Salgueiro/ PE.

23 Entrevista realizada em 19/08/03, com o Delegado da Polícia - Sr. Dr. Oswaldo Moreira, no seu gabinete na delegacia de Floresta/ PE.

24 Entrevista realizada em 28/08/03 na sede da Polícia Federal, em Recife/ Pernambuco.

25 Entrevista realizada em 23/08/03, com Celso P. Souza, ex- advogado e assessor do Pólo Sindical, no município de Paulo Afonso/ BA. 
Brasil não é apenas um país de trânsito, mas também de produção. Tal constatação vem a indicar a participação dos pólos produtores brasileiros no mercado internacional das drogas.

Para o bispo de Floresta ${ }^{26}$, a repressão na área só fez o plantio e a violência migrarem para outras áreas. A violência é marcante tanto pela sensação de insegurança devido aos constantes assaltos e saques realizados nas estradas, como pela própria atuação da polícia que em muitos casos obriga o trabalhador rural a participar das operações de erradicação, com ou sem remuneração, devido à dificuldade de acesso à caatinga.

Conforme relato dos trabalhadores, durante atividade preparatória para o Seminário de Levantamento de Direitos, o 'Polígono da Maconha do Brasil' é uma ficção criada pelo Estado. Essa territorialização aparece na opinião deles, como motivo para conseguir financiamento para as políticas de segurança pública, reduzidas ao armamento e a repressão, sem que haja um efetivo investimento na geração de políticas sociais e agrícolas para impedir o ingresso do trabalhador no mercado do narconegócio. Os milhões gastos na repressão e na militarização consequentemente, deveriam ser investidos em políticas preventivas, deslocando a atuação da repressão. Segundo o delegado da Polícia Federal em Salgueiro, a cada operação de controle são gastos em média $R \$ 120$ mil reais.

A partir das entrevistas percebe-se que o maior prejudicado, não só sob o âmbito financeiro, é o trabalhador rural, único preso e condenado como traficante. $O$ financiador, aquele que centraliza e distribui as sementes, os adubos, os fertilizantes, a alimentação e o armamento, nunca - ou quase nunca - é preso.

Os filhos dos reassentados que criaram o Pólo como sua ferramenta de luta e de demanda de direitos, eram muito pequenos na época para incorporarem esse espírito de herança na luta depois de dez anos, com os pais impedidos de produzir (sem a conclusão dos sistemas de irrigação) ganhando um vale pecuniário para "não trabalhar como agricultores" em sua própria terra. Também perderam a identidade de trabalhador rural ou o senso de dignidade e de integração com a terra como meio de vida e de cultura, porque não presenciavam a vitória de seus pais como lavradores. De outro lado, sua identidade se forjava cada vez mais pela mídia com forte apelo pela valorização da sociedade de consumo, enquanto o mercado de 
trabalho trazia a ilegalidade ocupando o vazio deixado pelas ofertas estruturais de emprego, movidas por uma economia local que não os incluía.

Segundo um jovem ${ }^{27}$, filho de reassentado, "quando se iniciou esse processo todo, eu era uma criança e hoje já tenho 16 anos. Dizem que somos bandido, mas não é verdade. Talvez, muitos tenham virado bandido pela omissão, pela demora em se resolver os problemas. E se hoje são é em função de algumas condições de vida que não nos foram dadas, e é isso que a gente hoje está dizendo aqui".

Aqueles que se sujeitam ao 'narcoplantio' são plantadores de ofício, conhecedores da terra, mas que não tem acesso aos meios de produção, e, assim, ficam a mercê do poder local. São trabalhadores rurais sem perspectiva de emprego no mercado legal, apenas no ilícito. Segundo um trabalhador: "Chamar de Polígono da Maconha faz com que os produtores da região sejam bandidos, traficantes e não plantadores - trabalhadores explorados pelo chefão, que às vezes não se sabe quem é" 28.

A lei é genérica e abstrata, porém a aplicação da pena está diretamente relacionada com a concretude do crime, a gravidade do dano social gerado pela ação ou omissão, as conseqüências do ato e, principalmente, a culpa do agente. Será o dano social causado pelos trabalhadores presos nas roças maior do que os efeitos das próprias políticas exclusivas de erradicação e repressão?

\section{A APLICAÇÃO DA LEI}

O crime é uma decisão política do Estado, em que ora determinadas condutas são consideradas lesivas à sociedade e, em outros momentos, o deixam de ser. Em sentido amplo, o crime corresponde ao ilícito penal, ou seja, é toda conduta humana, típica, ilícita, culpável e que, em decorrência, a lei contrapõe uma pena como sanção específica. Se não houver dano social, o Estado não pode reprimir.

26 23/08/03 entrevista com Dom Adriano, na Diocese de Floresta/ PE.

27 Fala durante Seminário de Levantamento de Direitos das Trabalhadoras e dos Trabalhadores Rurais do Submédio do São Francisco, realizado no auditório da Chesf, Paulo Afonso/ BA: 2003.

28 Fala de trabalhador rural durante o Seminário de Levantamento dos Direitos 
A tipicidade é a incidência de uma ação ou omissão ao tipo legal, ou seja, ao que está descrito na lei. Representa uma relação de ajuste entre determinado fato e o que está enunciado como conduta proibida no tipo. Sua função é gerar garantias à sociedade e impor um limite ao Estado em sua atividade persecutória. O crime é um fato típico, que tem como resultado a lesão de um bem ou interesse jurídico penalmente tutelado. A relação de causalidade objetiva entre $o$ agente e o resultado é indeclinável condição de toda infração penal. A ilicitude é a contradição do fato com o ordenamento jurídico, de modo a criar uma situação de dano ou perigo à coletividade. Via de regra, toda conduta ilícita é típica. Entretanto, nem toda conduta típica será ilícita, pois existem causas que excluem a ilicitude do ato. A culpabilidade faz com que o fato típico e a priori ilícito, seja reconhecido enquanto crime. É a exigibilidade de uma conduta diversa. Porém, se não é possível exigir do agente uma prática diferenciada da que foi realizada, mesmo em conflito com que o que está descrito no tipo penal, não há que se falar em culpabilidade e, portanto, não há crime. Surge o elemento subjetivo na definição do crime, baseado numa situação concreta que justifique a violação do tipo. O juízo de culpabilidade fundamenta-se na junção dos seguintes pressupostos: a imputabilidade, ou seja, um conjunto de fatores bio-psiquicos que tornam a pessoa consciente e capaz de auto-governo; o potencial de consciência da ilicitude, ou seja, é culpável quem assimila a conduta proibida e a pratica; e a exigibilidade de conduta diversa.

A excludente de ilicitude, pelo estado de necessidade, ou a inexigibilidade de conduta diversa, para excluir a culpabilidade, são algumas alternativas possíveis para se atribuir um tratamento legal mais justo e próximo à realidade social do trabalhador rural.

O sujeito a quem dedico essa reflexão, é o jovem, filho de reassentado, que viu os meios de vida e de cultura da reprodução familiares serem totalmente inundados, que cresceram distanciados da terra, do seu ofício de trabalhador rural, sem perspectiva de trabalho, emprego ou renda. Para ele, o cultivo da maconha aparece como alternativa econômica que irá permiti-lo ter acesso aos meios de produção.

Conforme apresentado, os indícios da presença da maconha na região, enquanto cultura de subsistência, remontam a década de 1950. A partir da década de 1980 sua produção vai adquirindo escala comercial. Com o processo de 
modernização no campo é que a produção da maconha vai ser incorporada ao narcoagronegócio ${ }^{29}$ de forma orgânica e administrativa. A cadeia produtiva inicia-se de forma legal, através dos insumos necessários à produção, passa pela ilegalidade no momento da produção e do comércio e volta para a legalidade, através do sistema financeiro.

O Estado, ao detectar a migração da escala produtiva, idealiza um modelo de intervenção que conjuga a repressão com o desenvolvimento de políticas sociais, mas que, na prática, não gera efeitos positivos. Ao contrário, os ilícitos múltiplos cometidos pelo Estado só fizeram piorar a condição daqueles que já estavam penalizados pela realidade social. Refiro-me ao abandono promovido pelo Estado aos pequenos agricultores no momento em que suspendeu todas as linhas de crédito com o escândalo da mandioca; à ociosidade imposta quando impediu - e ainda impede - que tivessem acesso a terra e aos meios de produção; à falta de compromisso social com aquela população por não finalizar os projetos de irrigação dos reassentamentos; à impunidade que sempre esteve presente na região; e, ainda, ao modelo econômico que privilegia a concentração de riquezas. Danos, aparentemente subjetivos e invisíveis, mas que no concreto só permitem um maior penalização dos já excluídos.

O Estado, ao tempo em que criminaliza os trabalhadores rurais por estarem plantando uma erva - que definiu como ilícita - deveria ser acionado pela sua responsabilidade no abandono daquela população.

Embora idealizada para atuar em duas frentes - na repressão e na reforma agrária - parece que grande parte do empenho está voltado à repressão. As inúmeras dificuldades operacionais - como a irregularidade fundiária, a burocratização do acesso aos créditos, a dificuldade de se localizar o proprietário, o tamanho das áreas etc - fazem com que a implementação da reforma agrária enquanto projeto alternativo ao ingresso do trabalhador no narcoplantio, não seja bem sucedido. E, mesmo considerando a quantidade de maconha apreendida nos anos de funcionamento da estrutura estatal do Polígono, não dá para se falar em sucesso. Afinal não dá para desprezar os índices de violência, furtos contra o patrimônio e a mortalidade infanto-juvenil. Além disso, a principal estratégia da

29 Para valer-me de expressão utilizada por RIBEIRO, Ana Maria Motta. Sociologia do narcotráfco na América Latina e a questão camponesa. In: RIBEIRO, Ana Maria Motta; IULIANELLI, J. Atílio lulianelli (Org.). 
polícia, que é a de atribuir prejuízo financeiro, aguardando os períodos de colheita para a erradicar, parece não surtir os devidos efeitos.

O trabalhador rural que se envolve com o narcoplantio o faz por uma necessidade conjuntural. Sem perspectiva de sobrevivência ou mesmo de melhoria de vida, constituem um exército de excluídos, miseráveis, facilmente cooptados pelo sistema ilegal. Eles se sujeitam às piores formas de trabalho, ao risco do trabalho no narconegócio, ficam de três a quatro meses presos nas áreas do plantio, sem ver a família, mulher ou filho, comendo em fogão de tijolo, dormindo no chão ou em redes, morando debaixo de lonas pretas, carregando nas costas, latões d'água de 40 litros (20 de cada lado), e ainda sendo obrigados a fazer a vigília armada para evitar furtos dos bandos inimigos.

As relações de trabalho no campo tendem a ser bastante precárias, porém a ilicitude que envolve a atividade, faz com que as condições de trabalho sejam ainda mais degradantes. Os trabalhadores rurais no Submédio não podem plantar maconha porque ela é considerada nociva à sociedade. Portanto, o bem jurídico tutelado com a prisão do trabalhador rural é a saúde pública. Entretanto, este, ao se envolver com o plantio, está lutando pela sobrevivência - a sua e de sua família. Temos então um conflito de bens jurídicos.

O homem e sua existência social concreta - os valores sociais e culturais e os interesses preponderantes - estão no centro da experiência jurídica-penal, principalmente no juízo da culpabilidade, cuja essência é a reprovabilidade - ou seja, quando se espera do agente um outro tipo de atitude. É uma ponderação de bens jurídicos em conflito. Ela parte da consideração, em termos concretos, da experiência social dos suspeitos e das oportunidades que thes foram dadas, correlacionando sua própria responsabilidade a uma responsabilidade geral do Estado que vai the impor uma pena. Será que, considerando todo o contexto histórico e as razões concretas que levam o trabalhador a cultivar maconha, seria razoável exigir um comportamento diverso?

A minha primeira hipótese é que para o trabalhador rural seja aplicada a excludente de culpabilidade, pela inexigibilidade de conduta diversa. Em não sendo aceita, que seja excluída a ilicitude pelo estado de necessidade, ou ao menos, que esta seja utilizada como atenuante no momento da aplicação da lei. $O$ que é 
inadmissível é que ao trabalhador rural seja imposta a mesma penalidade atribuída àquele que controla a cadeia produtiva. Ao contrário, a lei deveria expressamente reconhecer a realidade a que está sujeito o trabalhador. Sobretudo pela dívida social que o Estado tem com aquela população.

Para a aplicação da lei abstrata ao caso concreto, faz-se necessário uma interpretação da legislação, a partir do método lógico. No momento da aplicação da lei deve-se considerar uma série de elementos alheios ao aspecto literal para a fixação da vontade objetiva que a norma apresenta. A sentença condenatória não pode ser apenas legalmente correta e socialmente desastrosa.

Assim, se o objetivo da norma é tutelar a saúde pública, será a prisão do trabalhador rural o meio mais eficaz? As condições de sobrevivência naquela região fazem com que haja um exército de excluídos a serviço do narconegócio. "Não se pode reprimir com um 'desastre' o que a lei em tese, considera ofensivo, mas que a comunidade afetada, em concreto, reputa inofensivo" ${ }^{\text {30. }}$

Temos um conflito da lei com a realidade social. O que a lei determina como sendo proibido é o que permite ao trabalhador rural ter acesso aos meios de produção do campo, é saída para sua sobrevivência e de sua família.

\section{CONSIDERAÇÕES FINAIS}

O Pólo Sindical, talvez por estar vivendo os efeitos diretos da política proibicionista, se apresenta como um dos poucos movimentos sociais no Brasil, que se propõem a fazer o enfrentamento da questão. Como em todo processo de discussão, seu convencimento está em constante transformação. Na época do despertar da questão, o seu posicionamento era no sentido de exigir do governo mais policiamento e repressão. Passados alguns anos, discutindo e sofrendo os impactos diretos desta política, hoje se propõem a denunciar os seus efeitos e a cobrar um tratamento diferenciado aos trabalhadores rurais presos.

Refletir esta temática no âmbito da América Latina, nos permite perceber como por trás da "guerra às drogas" existe todo um universo de questões diretamente relacionadas às disputas territoriais pelo domínio das fontes naturais, da água, do petróleo e do gás natural. Populações inteiras são impactadas na sua 
saúde, na sua qualidade de vida, nos seus valores tradicionais, sob o pretexto da política de erradicação da folha da coca. Nos países andinos, os movimentos sociais, sob o lema "Nossa coca não é cocaína", organizam suas estratégias de resistência e defesa da soberania nacional. Na Bolívia, o movimento dos cocaleiros - reunidos em torno da Federação do Trópico de Cochabamba - sofre de forma mais direta os efeitos da política proibicionista, onde a lei de combate às drogas e a Lei de Segurança Nacional são utilizadas pelo Estado para criminalizar e conter o movimento social. Organizados contra a repressão, pela legalização e por um projeto político-econômico-social, resistem e lutam para alterar a estrutura de poder.

Os movimentos sociais são por essência emancipatórios, trazem novos valores sociais e culturais, cuja legitimidade se constrói a partir da vivência de seu próprio objeto. Por estarem produzindo novos paradigmas, rompendo com os interesses da hegemonia política, são criminalizados e perseguidos. Novamente temos a influência dos meios de comunicação e da grande mídia na construção do senso comum. Para garantir fortes interesses comerciais, atribui a estes sujeitos históricos terminologias pejorativas e desqualificadoras, velando as injustiças que este modelo excludente produz.

A sociedade precisa rever os valores que reproduz, mesmo quando são nitidamente conflitantes com o que a realidade vivenciada por ela. A política proibicionista, sob o pretexto da incolumidade da saúde pública promove um alarde social, pois para isso tem que combater o narcotráfico. Assim, não se discutem os reais efeitos das drogas, sejam elas lícitas ou ilícitas, na saúde do indivíduo. Como também não se discutem temas como o direito de liberdade de cada um de usar o seu corpo e sua mente da melhor forma que lhe aprouver; os meios de produção das substâncias que hoje estão sendo consumidas por milhares de pessoas e os elementos que a elas são misturados.

As razões que levam historicamente a humanidade a consumir substâncias - lícitas ou icilítas - que entorpeçam a razão estão diretamente vinculadas aos contextos históricos específicos. 


\section{BIBLIOGRAFIA}

ACSERALD, Gilberta. Drogas, violência, direitos e democracia. Relatório Comitê Brasil. Belo Horizonte: Fórum Social Brasileiro-FSB: 2003.

ARAUJO, Maria Lia Correia de. Participação Política: Entre o Conflito e a Negociação. In: ARAÚJO, Maria Lia Correia; NETO, de Magda de Caldas; LIMA, Ana Eliza Vasconcellos (Org.). Sonhos submersos. Recife: Fundação Joaquim Nabuco: Ed. Massangana, 2000.

BARATTA, Fernando. Prefácio. In: MALAGUTI, Vera B. Difíceis Ganhos Fáceis. Drogas e Juventude pobre no Rio de Janeiro. Rio de Janeiro: Instituto Carioca de Criminologia: Ed. Revan, 2003.

BARRETO, Menna. O desafio das drogas e o direito. Rio de Janeiro: Ed. Renes, 1971.

BATISTA, Nilo. Introdução crítica ao direito penal brasileiro. 8.ed. Rio de Janeiro: Editora Revan, 2002.

IULIANELLI, Jorge Atílio Silva. Análise (curta) dos confrontos recentes do Pólo Sindical do Sumédio São Francisco: quando o inimigo é difuso ou criminoso. In: Caderno CEAS, no 185. Salvador: 2000.

IULIANELLI, Jorge Atílio Silva. O gosto bom do bode: juventude, sindicalismo, reassentamento e narcotráfico no Submédio. In: RIBEIRO, Ana Maria Motta; IULIANELLI, J. Atílio (Org.). Narcotráfico e violência no campo. Rio de Janeiro: DP\&A, 2000.

KARAM, Maria Lúcia. "Redução de Danos, Ética e Lei: os danos da política proibicionista e as alternativas compromissadas com a dignidade do indivíduo". In: Christiane Moema Alves Sampaio, Marcelo Araújo Campos (Org). Drogas, Dignidade \& Inclusão Social. A lei e a prática de redução de danos. Rio de Janeiro: Aborda, 2003.

RIBEIRO, Ana Maria Motta. Sociologia do narcotráfco na América Latina e a questão camponesa. In: RIBEIRO, Ana Maria Motta; IULIANELLI, J. Atílio lulianelli (Org.). Narcotráfico e violência no campo. Rio de Janeiro: DP\&A, 2000.

RIBEIRO, Ana Maria Motta. Sindicalismo, barragens e narcotráfico. In: MOREIRA, Roberto José; COSTA, Luiz Flávio de Carvalho (Org.). Mundo rural e cultura. Rio de Janeiro: Mauad, 2002.

SCOTT, Parry R. Uma mancha nos perímetros irrigados: economia política na sub-regionalização no nordeste brasileiro. In: ZARUR, George de Cerqueira Leite (Org.). Região e nação na América Latina. Brasília: ed UNB, 2000.

VIANNA, Aurélio; LEROY, Jean Pierre; TAVARES, Ricardo. Lutas de resistência ou lutas por um novo modelo de sociedade? In: Proposta, Rio de Janeiro, n. 46, p.54-57, set./1990.

VIANNA, Aurélio Jr. O painel de inspeção do banco mundial para Itaparica. In: BARROS, Flávia (Org.). Banco Mundial, participação, transparência e responsabilização. A experiência brasileira com o painel de inspeção. Brasil: Rede Brasil, 2001. 
VIEIRA, Fernanda. Debate. In: SEMINÁRIO TRANSDISCIPLINAR EM SOCIOLOGIA E DIREITO. Niterói: PPGSD, 2003.

WACQUANT, Loïc. A tentação penal na Europa. In: Discursos sediciosos: crime, direito \& sociedade. Ano 7, no 11, 1ำ semestre de 2000. Rio de Janeiro: Ed. Revan: Instituto Carioca de Criminologia, 1998. 